\title{
Berufsstand diskutiert zunehmend globale zahnärztliche Themen
}

\begin{abstract}
Zum Weltzahnärztekongress der World Dental Federation (FDI) haben sich im September Vertreter aus über einhundert Ländern in der polnischen Universitätsstadt Poznan getroffen. In den Diskussionen ging es um eine gemeinsame Linie zur Verbesserung und Strukturierung der zahnärztlichen Versorgung weltweit.
\end{abstract}

Diskutiert wurde in großer Runde über Stellungnahmen zur bakteriellen Kontamination von Dentalsystemen, zu minimalinvasiven Behandlungen, sogenannten Graumarktprodukten und evidenzbasierter Zahnmedizin. Im Fokus standen darüber hinaus erneut die Zahnarzt-Patienten-Beziehung, Prävention und die Behandlung von Menschen mit Behinderung. Ein weiteres, intensiv diskutiertes Thema war die Sport-Zahnmedizin. Dabei ging es neben Methoden zur Verhinderung von Sportverletzungen auch um Dopingeffekte durch vom Zahnarzt verordnete Medikamente.

\section{Deutsche Vertreter in Ämtern bestätigt}

Zurückgezogen wurde ein Statement zur Einbeziehung von privaten und öffentlichen Leistungsträgern als sogenannte „third party" in die Arzt-Patienten-Beziehung. Hierin sahen gerade die deutsche Delegation unter Leitung von Dr. Peter Engel, Präsident der Bundeszahnärztekammer, und auch die Vertreter des Freien Verbandes Deutscher Zahnärzte (FVDZ) die Gefahr der Einmischung in die freie Berufsausübung.

Bei den Neuwahlen der FDI-Gremien wurden aus der deutschen Delegation im Practice Committee Dr. Michael Sereny und im Education Committee Dr. Jürgen Fedderwitz in ihren Ämtern bestätigt.

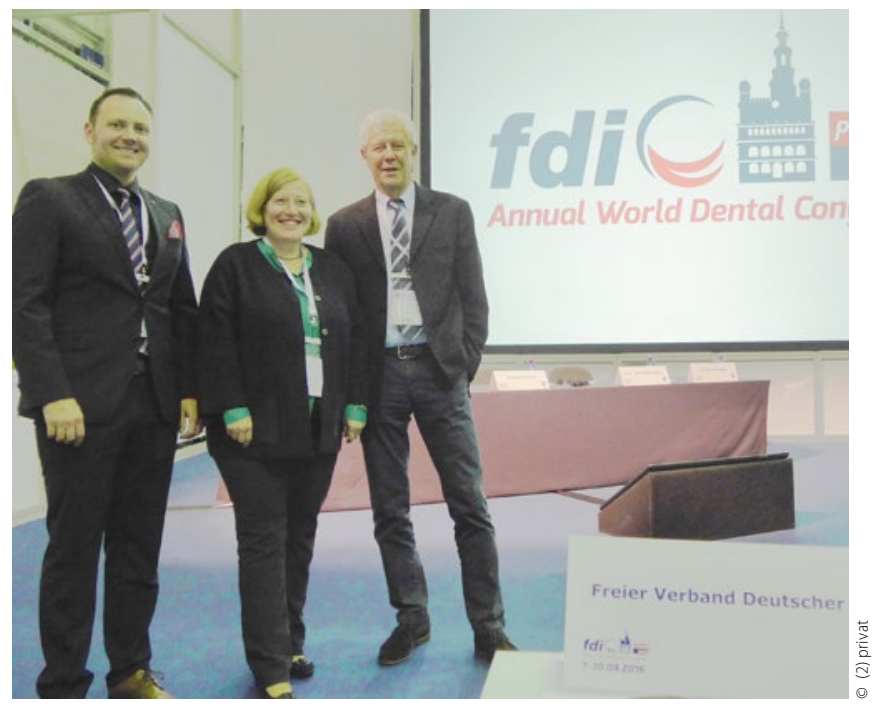

Delegation des FVDZ in Poznan: Dr. Thomas Wolf (links), Dr. Gudrun Kaps-Richter und Dr. Ernst-Jürgen Otterbach

\section{ERO tagt mit 35 Staaten}

Während des mehrtägigen FDI-Kongresses tagte gleichzeitig ihre europäische Unterorganisation ERO mit der Teilnahme von 35 Staaten. Unter Leitung der neuen polnischen ERO-Präsidentin Dr. Anna Lella berichteten die Arbeitsgruppen über ihre Tätigkeiten auf der europäischen Bühne.

Dr. Ernst-Jürgen Otterbach, Chairman der Arbeitsgruppe Liberal Dental Practice, referierte über den Stand einer Umfrage, die über die Organisationsstrukturen der Zahnärzteschaft in den einzelnen Ländern Auskunft geben soll. Über die Befragung will die Gruppe herausfinden, welche Trends und Entwicklungen sich in Hinblick auf neue Berufsausübungsformen abzeichnen. Eine Zusammenfassung der Ergebnisse wird die Arbeitsgruppe auf der nächsten ERO-Vollversammlung im April 2017 in Genf präsentieren.

„Es ist festzustellen, dass sich unser Berufsstand unter dem Trend einer sukzessiven Globalisierung zunehmend mit Herausforderungen konfrontiert sieht, die gemeinsame Lösungen benötigen", betonte Otterbach. Ein Wissens- und Erfahrungstransfer über die Grenzen der Nationalstaaten hinaus - auf der Ebene der FDI/ERO - sei ein wichtiger Beitrag zu einer qualitativ hochwertigen Zahnheilkunde und dem Erhalt einer freien, eigenverantwortlichen Berufsausübung.

red

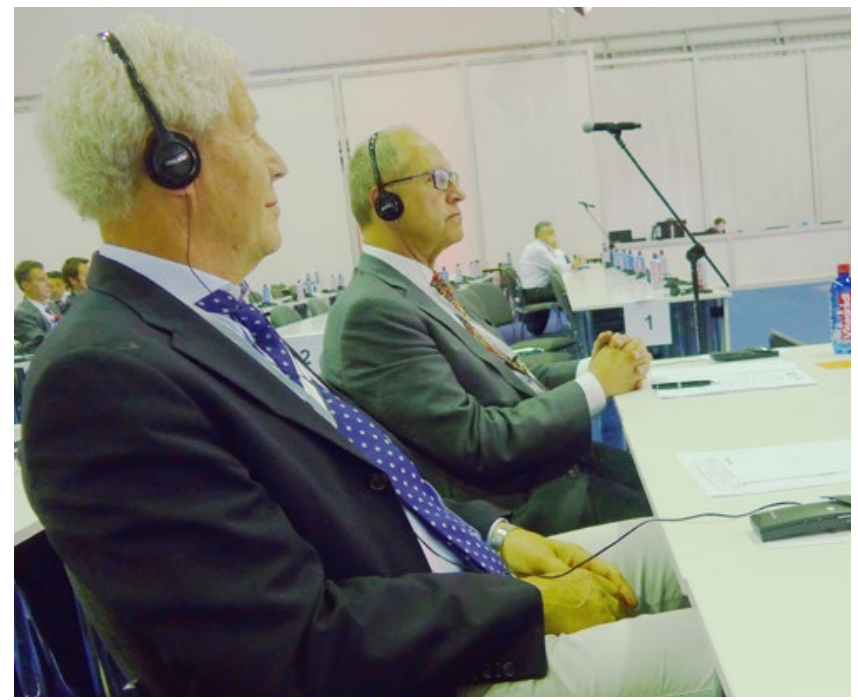

Interessante Disskussionen und Beiträge werden simultan übersetzt: Dr. Ernst-Jürgen Otterbach und Dr. Peter Engel hören zu. 